\section{Randomised trials in developing countries}

\author{
James A Berkley
}

Professor Trevor Duke and colleagues at the Centre for International Child Health, University of Melbourne, have made a remarkable contribution to international child health. Over the past 11 years, they have undertaken annual structured searches for published reports of controlled trials of interventions addressing child health in developing countries, and assembled summaries in a compendium that is easily accessible to clinicians, policymakers and research funders. They present an analysis of the controlled trials that have been included in these annual compendia. ${ }^{1}$

The results are encouraging: there has been a sevenfold increase in the number of trials published each year, providing a significant expansion in the evidence base for many common conditions, most notably the prevention and treatment of malaria. New knowledge of effective interventions from these trials has been generated alongside political will arising from the Roll Back Malaria initiative. Over the last 11 years, many endemic regions have experienced a decline in disease due to falciparum malaria.

The greatest number of published trials were on nutrition. Perhaps this is unsurprising given that recent estimates suggest that undernutrition causes $45 \%$ of childhood mortality, principally by increasing the likelihood of common life-threatening infectious diseases. Nearly three-quarters of nutritional intervention trials were of micronutrients. However, in the 2013 Lancet series on maternal and child nutrition, of the five nutrition-related interventions estimated to have the greatest potential to reduce childhood mortality, only one specifically involved a micronutrient: management of severe acute malnutrition (SAM); preventive zinc supplementation; promotion of breastfeeding; appropriate complementary feeding; and management of moderate acute malnutrition. $^{2}$ The recent WHO update on the management of SAM acknowledged that

Correspondence to Dr James A Berkley, KEMRI/ Wellcome Trust Research Programme, PO Box 230, Kilifi 80108, Kenya; Centre for Clinical Vaccinology \& Tropical Medicine, University of Oxford, Old Road, Headington, Oxford OX3 7L, UK;

jberkley@kemri-wellcome.org there had been very few controlled trials and, therefore, the evidence underlying their recommendations was, in general, of very low quality. There have also been relatively few trials on improved breastfeeding and complementary feeding in early life. These are areas urgently requiring further evidence from controlled trials and are increasingly likely to address broad strategies than focus on single nutrients.

Another notable mismatch between the burden of morbidity and mortality, and the available evidence from clinical trials is neonatal illness. As mortality declines more quickly in older age groups worldwide, the proportion of mortality in the neonatal period is increasing and is approaching half of all childhood mortality in many regions in developing countries. The main causes of neonatal mortality in developing countries are preterm birth, neonatal sepsis, and intra-partum complications including birth asphyxia. These problems are usually determined by a complex set of background risk factors and limitations in preventive and treatment resources. The greatest improvements are likely to come about from multifaceted interventions including community-based strategies, as has recently been shown in Malawi and in Pakistan. ${ }^{3} 4$

The design of clinical trials that alter policy and practice usually depends on observational studies of the aetiology or modifiable determinants of illness that generate hypotheses on potentially effective interventions. Unlike most developed country settings, the vast majority of health facilities that provide care for sick children, or are responsible for public health measures in the developing world lack the resources to determine the aetiology of serious illness in children. Some pathogens, such as Haemophilus influenzae, Streptococcus pneumoniae and common viruses, such as respiratory syncytial virus and rotavirus may be invisible to health professionals who do not have the facilities to accurately detect them. The burden of paediatric tuberculosis is largely unknown in many regions and is difficult to assess with current diagnostic tools. As candidate vaccines emerge for other pathogens, such as Group A and Group B Streptococcus, gaps in basic clinical epidemiology including the burden of disease and distribution of serotypes need to be filled in order that appropriate trials of vaccines may be undertaken.

During the 11 years reviewed, there has been an increasing proportion of trials for which the corresponding authors are based in developing countries, suggesting that local capacity to undertake trials is being enhanced. Importantly, the evidence for interventions resulting from clinical trials is frequently taken up into policy first in the countries where the trials have been conducted because of the engagement that they generate and obvious local applicability of results. Examples include bacterial conjugate vaccines and treatment of malaria with artemisinin derivatives.

However, in developing countries, there is often limited opportunity for local clinicians to gain the skills needed to conduct high-quality trials. Participation in large multicentre clinical trials has played a significant role in generating local capacity. In Africa, the recent RTS,S malaria vaccine trials and large trials of antimalarial treatments have enhanced skills and facilities in local centres. There are several initiatives that support local investigator-led clinical trials. Organisations such as the Global Health Trials Network (https:// globalhealthtrials.tghn.org/) currently provide resources for career development for clinical trials professionals including trial coordinators, data managers and monitors, as well as resources including standardised protocols and data collection tools. Open source software is available for capture and managing data for trials that meets international regulatory standards. Support for capacity building in clinical trials is provided by the European \& Developing Countries Clinical Trials Partnership (EDCTP) and other funders. Local networks, such as the East African Consortium for Clinical Research (EACCR), based in Entebbe, Uganda, provide regional facilities for training in grant writing, trials design and management, good clinical practice, ethics, and organise cross-trial monitoring between participating centres, which decreases reliance of more expensive external commercial monitoring and other outsourcing services. There is considerable need to further develop national and regional clinical trials support units throughout the developing world. ${ }^{5}$

An important issue that is highlighted in the article is that all too frequently, interventions with strong evidence of efficacy and cost-effectiveness are not adequately taken up into policy or adequately implemented in practice. Examples include some of the simplest and least expensive interventions, such as zinc and oral 
rehydration solution, for diarrhoea and cord care for newborns. Research is needed at a national policy level, at districts and health facilities, and among individual clinicians to induce behaviour change. There are also areas where clinical trials of efficacy are not needed, including universal access to free healthcare, access to essential medicines, and ensuring food security. Trials that focus on health systems and cross-cutting strategies are essential in order to identify the best ways of implementing these.

In the next 11 years, it is likely that the number of clinical trials will continue to increase. The annual compendium of controlled trials in developing countries will therefore be an increasingly valuable resource... Long may it continue.

\section{Competing interests None.}

Provenance and peer review Commissioned; internally peer reviewed.
Open Access This is an Open Access article distributed in accordance with the Creative Commons Attribution Non Commercial (CC BY-NC 4.0) license, which permits others to distribute, remix, adapt, build upon this work non-commercially, and license their derivative works on different terms, provided the original work is properly cited and the use is noncommercial. See: http://creativecommons.org/licenses/ by-nc/4.0/

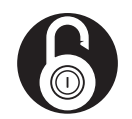

\section{OPEN ACCESS}

To cite Berkley JA. Arch Dis Child 2014;99:607-608.

Received 12 April 2014

Revised 25 April 2014

Accepted 26 April 2014

Published Online First 15 May 2014

\section{Sinked}

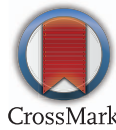

- http://dx.doi.org/10.1136/archdischild-2013-305702
Arch Dis Child 2014:99:607-608.

doi:10.1136/archdischild-2014-306163

\section{REFERENCES}

1 Duke T, Fuller D. Randomised controlled trials in child health in developing countries: trends and lessons over 11 years. Arch Dis Child 2014;99: 615-20.

2 Bhutta ZA, Das JK, Rizvi A, et al. Evidence-based interventions for improvement of maternal and child nutrition: what can be done and at what cost? Lancet 2013:382:452-77.

3 Colbourn T, Nambiar B, Bondo A, et al. Effects of quality improvement in health facilities and community mobilization through women's groups on maternal, neonatal and perinatal mortality in three districts of Malawi: MaiKhanda, a cluster randomized controlled effectiveness trial. Int health 2013;5:180-95.

4 Bhutta ZA, Soofi S, Cousens S, et al. Improvement of perinatal and newborn care in rural Pakistan through community-based strategies: a cluster-randomised effectiveness trial. Lancet 2011;377:403-12.

5 Siegfried N, Volmink J, Dhansay A. Does South Africa need a national clinical trials support unit? $S$ Afr Med J 2010;100:521-4. 